\title{
PREVALENCE OF DENTAL CARIES IN SCHOOL GOING CHILDREN OF DIBRUGARH TOWN, ASSAM
}

\author{
Hemen Sharma1, Alak Barua², Puspita Barman³, Dipanjal Saikia ${ }^{4}$
}

${ }^{1}$ Demonstrator, Department of Community Medicine, Silchar Medical College and Hospital.

${ }^{2}$ Professor, Department of Community Medicine, Assam Medical College and Hospital.

${ }^{3}$ Demonstrator, Department of Community Medicine, Silchar Medical College and Hospital.

${ }^{4}$ Associate Professor, Department of Dentistry, Assam Medical College and Hospital.

ABSTRACT
BACKGROUND
Dental caries is a major public health concern owing to their higher prevalence and their effects on the individual's quality of life.
The problem is dreadful, particularly among school children.
Objective- To estimate the prevalence of dental caries among school going children aged $5-15$ years studying in schools of
Dibrugarh Town.

\section{MATERIALS AND METHODS}

A cross-sectional study was undertaken amongst the school students aged $5-15$ years enrolled in schools of Dibrugarh town, Assam. Students were checked for presence of dental caries and were interviewed with a predesigned and pretested schedule.

\section{RESULTS}

Total 351 students participated in the study and the overall prevalence of dental caries was found to be $62.1 \%$. The prevalence of dental caries was significantly higher among students belonging to lower socio-economic group. The prevalence was significantly lower among students who had brushing habits twice a day as compared to those having brushing habit once daily. Students having more than one sibling had higher prevalence as compared to students having no or one sibling. The prevalence of dental caries was significantly lower among students studied in private school.

\section{CONCLUSION}

It is concluded that the prevalence of dental caries in the present study is on the higher side. The study highlights the need of awareness among students regarding the advantages of good oral hygienic practises with regular monitoring of children for common dental problems at the school level.

\section{KEYWORDS}

Dental Caries, Prevalence, School Children.

HOW TO CITE THIS ARTICLE: Sharma H, Barua A, Barman P, et al. Prevalence of dental caries in school going children of Dibrugarh town, Assam. J. Evolution Med. Dent. Sci. 2017;6 (42):3320-3323, DOI: 10.14260/Jemds/2017/719

\section{BACKGROUND}

Dental caries is one of the most prevalent oral disease affecting children and adolescents in the world today.(1) The prevalence of dental caries in a population is influenced by a number of factors such as age, sex, socioeconomic status, ethnicity, dietary patterns and proper oral hygienic practises. Although, the prevalence of dental caries in the developing countries was low until the recent years, but very lately there has been an increase in its prevalence. This increase has largely been contributed by factors like high consumption of sugars and inadequate use of fluorides, etc.(2) However, a decline in the prevalence of dental caries has been observed in most industrialised countries, which could be attributed to population based preventive programs such as the use of fluorides, reducing sugar intake and maintaining proper oral hygiene.(3)

Financial or Other, Competing Interest: None.

Submission 06-04-2017, Peer Review 13-05-2017,

Acceptance 19-05-2017, Published 25-05-2017.

Corresponding Author:

Dr. Hemen Sharma,

Department of Community Medicine,

Silchar Medical College and Hospital,

Cachar, P.O-Ghungoor - 788014, Assam.

E-mail: hemensharma57@gmail.com

DOI: $10.14260 /$ jemds $/ 2017 / 719$
A very extensive and comprehensive National Health Survey conducted in 2004 throughout India had observed that the prevalence of dental caries was $51.9 \%, 53.8 \%$ and $63.1 \%$ in children aged 5 years, 12 years and 15 years respectively.(4) This survey report recommended that a preventive dentistry programme should be initiated to address such high prevalence rate of dental caries. For the effective implementation of a comprehensive preventive oral healthcare programme, schools provide a proper forum to reach the school children and through them their families and community members. Till date very few studies have been conducted to assess the prevalence of dental caries and the oral hygienic status amongst the school children of Dibrugarh town.

\section{MATERIALS AND METHODS \\ Study Design and Setting}

A cross-sectional study was conducted between June 2014 and May 2015 on 351 school going children of Dibrugarh town, Assam. The study area selected includes 105 schools in the urban area of Dibrugarh town.

\section{Sampling Method and Sample Size}

Considering $65.6 \%$ prevalence of dental caries among school going children,(5) $10 \%$ relative error and alpha $=0.05$, the sample size required was calculated and rounded off to 350 . Number of school children aged 5 - 15 years included from each school was determined by using proportional allocation. 


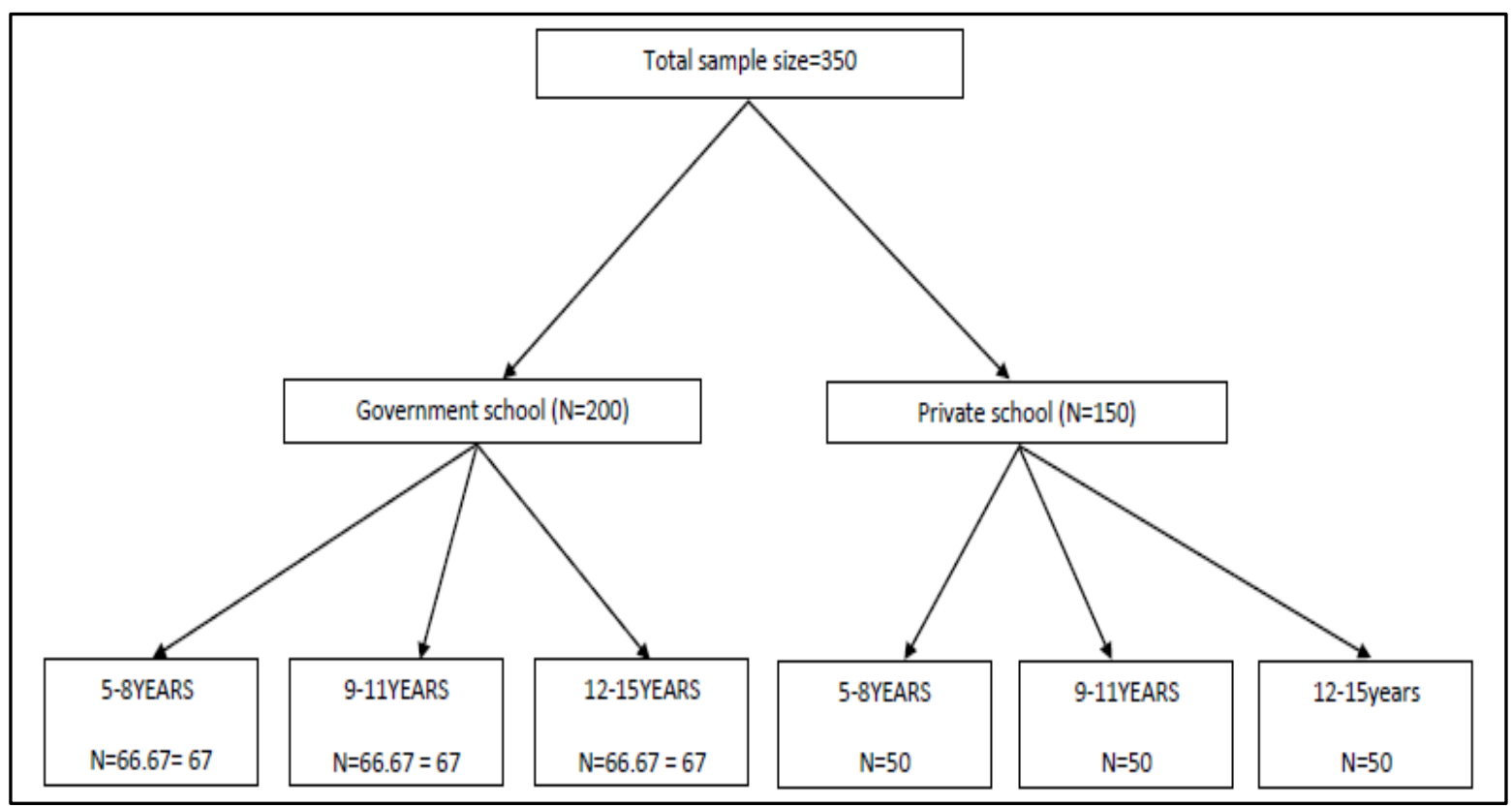

In allocating the students of the government schools into the three age groups because of rounding off, the total number of students became 201 instead of 200 and as such the overall sample size was inflated to 351 .

\section{Data Collection}

The selected schools were visited on prefixed dates and relevant data was collected in a pre-designed and pre-tested schedule.

\section{Assessment of Dental Caries}

Assessment of Dental caries amongst children was done by intra-oral examination of the teeth. The children who had given prior assent to participate in the study were examined within their school, usually in the school corridor. Oral examination was conducted using the dental mirror and dental probe/dental explorer (No. 23). All the teeth were examined in a systematic manner using the International FDI two-digit nomenclature to identify each primary and permanent tooth. Standard dental terminology was used to identify each tooth surface. An average number of 10 school children were examined per day. All the examinations were carried out by a trained Dental Surgeon.

Prior to each and every oral examination, the instruments were kept in Cidex solution for disinfection and sterilisation. Chlorhexidine mouthwash was diluted by adding potable water in the ratio of 1:9 dilutions. The schoolchildren were allowed to sit on a chair, where sufficient natural daylight was available. The children were asked to rinse their mouth thoroughly before examination, then the teeth were dried with cotton swab and the general condition of oral cavity, condition of the teeth and the presence of dental caries were recorded. Immediate care was instituted in children having minor teeth and gum bleeding and referral was made to the Department of Dentistry, Assam Medical College and Hospital.

\section{Working Definitions}

Dental Caries: Dental caries was diagnosed according to the presence of "Decayed/Filled Teeth" present according to the WHO oral health survey 1999.
Missing teeth were not considered because of natural exfoliation occurring in young children. Dental caries in children was diagnosed when the following were present-

\section{a. Decayed Tooth}

Caries was regarded as present when a cavity was seen in a pit, fissure or smooth surface of a tooth.

\section{b. Filled Teeth}

Teeth which showed evidence of permanent restoration along with one or more areas that are decayed.

The proportion of children with evidence of caries were determined and recorded accordingly in pre-designed schedule.

\section{Statistical Analysis}

The data generated were entered in Microsoft Excel sheet and copied into a SPSS sheet (version 16.0). The analysis was done using SPSS (version 16.0). Chi square test was used to test the statistical significance between different groups.

\section{RESULTS}

In the present study which comprised of 351 study participants, $59 \%$ were boys and $41 \%$ were girls. The majority of the boys, i.e. $66.7 \%$ were in the age group of $9-11$ years. As far as socio-economic status is considered, using modified Kuppuswamy's scale 2014 majority belonged to socio-economic class II and III $(38.5 \%$ and $27.4 \%$ respectively). Only $7.1 \%$ students belonged to socioeconomic class I; $201 \quad(57.2 \%)$ students studied in government schools, while $150(42.8 \%)$ studied in private school. Majority $(63.2 \%)$ of the students had more than one siblings in their family. The students were asked about the habits and practices regarding the dental health; $75.2 \%$ students used to brush once daily, $22.5 \%$ students had the brushing habit of twice daily and only $2.3 \%$ students had the habit of brushing after every meal. The students were asked about the habit of rinsing of mouth with water after taking food. It was found that majority $(49.0 \%)$ had the habit of rinsing their mouth rarely, mainly after taking major meals, not after taking any other food; $45.3 \%$ student often rinsed 
their mouth after taking food and 5.7\% students replied that they rinsed their mouth always after taking any meal.

According to physical examination, 218 (62.1\%) students had dental caries. Prevalence of dental caries was assessed according to different socio-demographic parameters. It is seen that $70.9 \%$ of the students in the age group of $5-8$ years and $53 \%$ of the students in the age group of $12-15$ years had dental caries. So, prevalence of dental caries decreased with increase in age and this difference was found to be statistically significant $(p<0.05)$. It was seen that $59.0 \%$ of boys had dental caries as compared to $41.0 \%$ girls having the same problem. However, this difference was significant statistically. It was observed that prevalence of dental caries was highest $(100 \%)$ in socio-economic class $\mathrm{V}$, whereas it was lowest (44\%) amongst those who belong to socioeconomic class I and this difference was statistically significant. Prevalence of dental caries was found to be more (83.1\%) amongst the students, who studied in government schools in comparison to those (34\%) who studied in private schools, which was found to be statistically significant. Study subjects were assessed for prevalence of dental caries according to presence of siblings. It is seen that students having no sibling or one sibling were less commonly suffering from dental caries as compared to students having more than one sibling. Students were asked about their habit of brushing the teeth. It is seen that $60.7 \%$ of the students who used to brush twice a day had dental caries as compared to $64.0 \%$ of the students having habit of brushing the teeth once daily suffered from dental caries. This difference was statistically significant. Prevalence of dental caries was less (35\%) amongst students who always rinsed their mouth after

taking any kind of food in comparison to those (55.2\%) who only wash their mouth after taking major meal. This difference was found to be again statistically significant (Table 1 - 4).

\begin{tabular}{|c|c|c|c|}
\hline Socio-Demographic Parameter & Number & Percentage \\
\hline \multirow{3}{*}{ Age } & $5-8$ years & 117 & $33.3 \%$ \\
\cline { 2 - 4 } & $9-11$ years & 117 & $33.3 \%$ \\
\cline { 2 - 4 } & $12-15$ years & 117 & $33.3 \%$ \\
\hline \multirow{4}{*}{ Sex } & Male & 207 & $59 \%$ \\
\cline { 2 - 4 } & Female & 144 & $41 \%$ \\
\hline \multirow{4}{*}{ Socio-Economic Class } & Class- I & 25 & $7.1 \%$ \\
\cline { 2 - 4 } & Class- II & 135 & $38.5 \%$ \\
\cline { 2 - 4 } & Class- III & 96 & $27.4 \%$ \\
\cline { 2 - 4 } & Class- IV & 92 & $26.1 \%$ \\
\cline { 2 - 4 } & Class- V & 3 & $0.9 \%$ \\
\hline \multirow{4}{*}{ School } & Government & 201 & $57.2 \%$ \\
\cline { 2 - 4 } & Private & 150 & $42.8 \%$ \\
\hline \multirow{2}{*}{ Siblings } & $0-1$ & 129 & $36.8 \%$ \\
\cline { 2 - 4 } & $>2$ & 222 & $63.2 \%$ \\
\hline \multicolumn{3}{|c|}{ Table 1. Socio-Demographic } \\
\hline \multicolumn{3}{|c|}{ Characteristics of the Study Population } \\
\hline
\end{tabular}

\begin{tabular}{|c|c|c|c|}
\hline \multicolumn{2}{|c|}{ Parameter } & Number & Percentage \\
\hline \multirow{3}{*}{$\begin{array}{c}\text { Frequency of } \\
\text { Brushing Teeth }\end{array}$} & Alternate day & 0 & $0 \%$ \\
\cline { 2 - 4 } & Once a day & 264 & $75.2 \%$ \\
\cline { 2 - 4 } & Twice a day & 79 & $22.5 \%$ \\
\cline { 2 - 4 } & After every meal & 8 & $2.3 \%$ \\
\hline \multirow{3}{*}{$\begin{array}{c}\text { Mouth Rinsing } \\
\text { after taking Food }\end{array}$} & Always & 20 & $5.7 \%$ \\
\cline { 2 - 4 } & Often & 159 & $45.3 \%$ \\
\cline { 2 - 4 } & $\begin{array}{c}\text { Only after taking } \\
\text { major meal }\end{array}$ & 172 & $49 \%$ \\
\hline \multicolumn{3}{|c|}{ Table 2. Habits of the Study Population } \\
\hline
\end{tabular}

Table 2. Habits of the Study Population

\begin{tabular}{|c|c|c|c|c|c|}
\hline \multicolumn{2}{|c|}{ Socio-Demographic Parameter } & Caries Present & Caries Absent & Total & Significance \\
\hline \multirow{3}{*}{ Age } & 5 - 8 years & $83(70.9 \%)$ & $34(29.1 \%)$ & $117(100 \%)$ & \multirow{3}{*}{$\mathrm{P}<0.05$} \\
\hline & $9-11$ years & $73(62.4 \%)$ & $44(37.6 \%)$ & $117(100 \%)$ & \\
\hline & $12-15$ years & $62(53 \%)$ & $55(47 \%)$ & $117(100 \%)$ & \\
\hline \multirow{2}{*}{ Sex } & Male & $132(63.8 \%)$ & $75(36.2 \%)$ & $207(100 \%)$ & \multirow{2}{*}{$P>0.05$} \\
\hline & Female & $86(59.7 \%)$ & $58(40.3 \%)$ & $144(100 \%)$ & \\
\hline \multirow{5}{*}{$\begin{array}{c}\text { Socio-Economic } \\
\text { Class }\end{array}$} & Class- I & $11(44 \%)$ & $14(56 \%)$ & $25(100 \%)$ & \multirow{5}{*}{$\mathrm{P}<0.05$} \\
\hline & Class- II & $64(47.5 \%)$ & $71(52.5$ & $135(100 \%)$ & \\
\hline & Class- III & $59(61.4 \%)$ & $37(38.6 \%)$ & $96(100 \%)$ & \\
\hline & Class- IV & $81(88.1 \%)$ & $11(11.9 \%)$ & $92(100 \%)$ & \\
\hline & Class- V & $3(100 \%)$ & $0(0 \%)$ & $3(100 \%)$ & \\
\hline \multirow{2}{*}{ School } & Government & $167(83.1 \%)$ & $34(16.9 \%)$ & $201(100 \%)$ & \multirow{2}{*}{$\mathrm{P}<0.05$} \\
\hline & Private & $51(34 \%)$ & $99(66 \%)$ & $150(100 \%)$ & \\
\hline \multirow{2}{*}{ Siblings } & $0-1$ & $70(54.3 \%)$ & $59(45.7 \%)$ & $129(100 \%)$ & \multirow{2}{*}{$\mathrm{P}>0.05$} \\
\hline & $>2$ & $148(66.7 \%)$ & $74(33.3 \%)$ & $222(100 \%)$ & \\
\hline
\end{tabular}

Table 3. Association of Prevalence of Dental Caries with Socio-Demographic Characteristic of Study Population

\begin{tabular}{|c|c|c|c|c|c|}
\hline \multicolumn{2}{|c|}{ Parameter } & Caries Present & Caries Absent & Total & Significance \\
\hline \multirow{4}{*}{ Frequency of Brushing Teeth } & Alternate day & $0(0 \%)$ & $0(0 \%)$ & $0(100 \%)$ & \multirow{4}{*}{$\mathrm{P}<0.05$} \\
\hline & Once a day & $169(64 \%)$ & $95(36 \%)$ & $264(100 \%)$ & \\
\hline & Twice a day & $48(60.7 \%)$ & $31(39.3 \%)$ & $79(100 \%)$ & \\
\hline & After every meal & $1(12.5 \%)$ & $7(87.5 \%)$ & $8(100 \%)$ & \\
\hline \multirow{3}{*}{$\begin{array}{l}\text { Mouth Rinsing after taking } \\
\text { Food }\end{array}$} & Always & $7(35 \%)$ & $13(65 \%)$ & $20(100 \%)$ & \multirow[b]{3}{*}{$\mathrm{P}<0.05$} \\
\hline & Often & $116(73 \%)$ & $43(27 \%)$ & $159(100 \%)$ & \\
\hline & $\begin{array}{l}\text { Only after taking } \\
\text { Major Meal }\end{array}$ & $95(55.2 \%)$ & $77(44.8 \%)$ & $172(100 \%)$ & \\
\hline
\end{tabular}

\section{DISCUSSION}

Oral diseases have a profound effect on the general health and well-being of an individual. The impact of oral diseases in terms of pain and suffering, impairment of function and reduced quality of life is significant. Dental caries is one of the leading problems in school going children as well as in adults. 
The World Health Organisation (WHO) has recognised dental caries as a pandemic and reported its prevalence among school children to range from $60 \%-90 \%$.(1) The present study showed caries prevalence of $62.1 \%$ in 5 to 15 years old school going children. Joshi et al (2013) in their study in Vadodara city India observed that the prevalence of dental caries amongst school children of age 6 to 12 years was $69.2 \%,(6)$ which was higher than our study. Another study Joyson $M$ et al (2011) in their study in Chidambaram India observed that the prevalence of dental caries amongst $5-15$ years school going children was $63.83 \%$.(7) In the present study, the prevalence of dental caries amongst the study participants was more $(63.0 \%)$ in the boys compared to the girls (58.6\%). Similar to our study, Joshi N et al (2013) observed the prevalence of dental caries was $70.01 \%$ amongst boys and $68.22 \%$ amongst girls. Contrary to our study, Datta P et al (2013) in their study on dental caries in the school going children of age $13-14$ years in Sundarban India observed that the prevalence of dental caries was higher (76\%) among girls than boys, i.e. $68.8 \%{ }^{(8)}$

The present study found that prevalence of dental caries was significantly low among Socio-Economic Status (SES) Group I and II and it has steadily increased up to socioeconomic status $\mathrm{V}$ group. This suggests that the caries experience deteriorated with socio-economic status. Similar to our study, Sudha P et al (2005) found that the prevalence of caries was greater in the low socio-economic group when compared to the high socio-economic group.(9) These findings are in accordance with the observations of Singh et al (2006).(10) Reason for the high dental caries among the poor lower social economic class and among the public schools when compared to the high socio-economic group and private schools because awareness, easy accessibility for dentist and affordability towards the dental treatment and also having a literate mother, and having an advantageous socio-economic position while untreated decay was associated mainly to lower socio-economic position. These findings may indicate differences in access to health services and different levels of education on oral health. Prevalence of dental caries was significantly higher among children having more than one sibling. Usually when the number of children increases, less care is given to each child by the mother and the elder ones suffer most. As a result the prevalence of diseases related to hygiene increases. Students were asked about their habit of brushing the teeth and it was found that those participants who cleaned their teeth twice a day had less tooth decay as compared to those who cleaned their teeth once a day. Similar findings were reported from a study by Siraj A et al (2015) in North India that the prevalence of dental caries was more (37.3\%) amongst those who used to brush their teeth once in comparison to those who brushed their teeth twice, that is $14.8 \%$. The difference was found to be statistically significant.(11) Also Inamdar IF et al (2014) in their study on dental caries in Nanded, India observed that the prevalence of dental caries was less (19.51\%) amongst those who brushed their teeth twice or more daily in comparison to those who brushed their teeth once daily, that is $34.74 .(12)$

\section{CONCLUSION}

Dental caries is not only a medical problem, but also a social problem. Awareness regarding the advantages of good oral hygienic practises can be increased through proper health education of parents along with regular monitoring of children for common dental problems at the school level by the school teachers, because they are the role model for the students. Parents should be aware of the dental health of their children. Health education should also be incorporated within the regular activities of the school. Overall education, particularly female education could help in a big way to solve the problems in future.

\section{REFERENCES}

[1] Bansal R, Sharma S, Shukla AK, et al. Prevalence of dental caries among school children in Meerut. Asian Pacific Journal of Health Sciences 2015;2(1):84-8.

[2] Peterson PE, Bourgeois D, Ogawa H, et al. The global burden of oral diseases and risks to oral health. World Health Organization Bulletin 2005;83(9):661-9.

[3] Ahmed NA, Åstrøm AN, Skaug N, et al. Dental caries prevalence and risk factors among 12-year old schoolchildren from Baghdad, Iraq: a post- war survey. International Dental Journal 2007;57(1):36-44.

[4] National Oral Health Survey and Fluoride Mapping. An epidemiological. study of oral health problems and estimation of fluoride levels in drinking water. Dental Council of India, New Delhi 2004;32:67-78.

[5] Babu MMS, Nirmala SVSG, Nuvvula S. Oral Hygiene status of 7-12 year school children in rural and urban population of Nellore district. Journal of Indian Association of Public Health Dentistry 2011;18(3):1075-80.

[6] Joshi N, Sujan S, Joshi K, et al. Prevalence, severity and related factors of dental caries in school going children of Vadodara city - an epidemiological study. Journal of International Oral Health 2013;5(4):35-9.

[7] Moses J, Rangeeth BN, Gurunathan D. Prevelance of dental caries among 5-15 years school going children of Chidambaram. J Ind Dent Reasearch 2011;5(1):14651.

[8] Datta P, Datta PP. Prevalence of dental caries among school children in Sundarban, India. Epidemiology: an Open Access Journal 2013;3(4).

[9] Sudha P, Bhasin S, Anegundi RT. Prevalence of dental caries among 5 to 13 year old children of Mangalore city. Journal of Indian Society of Pedodontic and Preventive Dentistry 2005;23(2):74-9.

[10] Singh S, Kaur G, Kapila S. Dental disorders in primary school children of Faridkot city. Journal of Indian Dental Association 1985;57(8):304-8.

[11] Ahmad S, Md. Ahmad T, Agali CR. Assessment of factors determining oral health status among adolescents residing in an urban area of North India. International Journal of Advanced Research 2015;3(5):1420-6.

[12] Inamdar IF, Ubaidulla M, Tambe SH, et al. Study of oral health among adolescents in the field practice area of Urban health training centre, Nanded, India. Journal of Dental and Medical Sciences 2013;8(6):26-30. 